\title{
Mezitli Deresi Boyunca Biyojeokimyasal Anomalilerin İncelenmesi, Mersin
}

An Investigation of Biogeochemical Anomalies Along the Mezitli Stream, Mersin

\section{Ali BOZDOĞAN', Derya ÖZ1 ${ }^{1}$ Zeynep ÖZDEMİR ${ }^{1}$, Erkan DEMİR ${ }^{2}$, Zübeyde HATİPOĞLU BAĞCI ${ }^{1}$}

${ }^{1}$ Mersin Üniversitesi, Mühendislik Fakültesi, Jeoloji Mühendisliği Bölümü, MERSİN

${ }^{2} T M M O B$, Jeoloji Mühendisleri Odası Il Temsilciliği, Yenişehir, MERSIN

ÖZ

$\begin{array}{lll}\text { Geliş (received) } & : & \text { 14 Temmuz (July) } 2015 \\ \text { Düzeltme (revised) } & : & \text { 23 Aralı (December) } 2015 \\ \text { Kabul (accepted) } & : & \text { 28 Aralı (December) } 2015\end{array}$

Son yıllarda, biyojeokimyasal yöntemler maden aramalarında yaygın olarak kullanılmaktadır. Bu çalışmada, Mezitli Deresi (Mersin) boyunca doğal olarak yetişen Platanus orientalis (doğu çınarı) ve Phragmites australis (kamış) bitki türlerinde biyojeokimyasal anomalilerin saptanması amaçlanmıştır. Mezitli (Mersin) bölgesinde 8 istasyondan alınan P. australis ve P. orientalis bitkilerinin yaprak ve dal örnekleri ile bu istasyonlardan alınan toprak ve dere suyu örneklerindeki Li, B, Al, Ti, V, Cr, Mn, Fe, Co, $\mathrm{Ni}, \mathrm{Cu}, \mathrm{Zn}, \mathrm{As}, \mathrm{Se}, \mathrm{Rb}, \mathrm{Sr}, \mathrm{Mo}, \mathrm{Cd}, \mathrm{Sn}, \mathrm{Cs}, \mathrm{Ba}$ ve $\mathrm{Pb}$ için element düzeyleri, endüktif eşleşmiş plazmakütle spektrometrisi (ICP-MS) ile saptanmıştır. Bu analiz sonuçlarının istatistiksel olarak incelenmesi sonucunda, $P$. orientalis bitki türünün dalının $\mathrm{B}(\mathrm{n}=10, \mathrm{r}=0,76, \% 99$ güvenilirlikle $\mathrm{P}<0,01), \mathrm{Cr}(\mathrm{n}=12$, $\mathrm{r}=-0,67, \% 95$ güvenilirlikle, $\mathrm{P}<0,05), \mathrm{Sr}(\mathrm{n}=9, \mathrm{r}=0,72, \% 95$ güvenilirlikle, $\mathrm{P}<0,05)$ ve $\mathrm{Pb}(\mathrm{n}=11, \mathrm{r}=$ 0,63, \% 95 güvenilirlikle, $\mathrm{P}<0,05$ ) elementleri için belirtgen bitki olarak biyojeokimyasal prospeksiyonda kullanılabileceği saptanmıştır. Aynı zamanda $P$. australis bitki türünün yaprağının ise $\mathrm{Cu}(\mathrm{n}=11, \mathrm{r}=-0,66$, $\% 95$ güvenilirlikle, $\mathrm{P}<0,05), \mathrm{Cr}(\mathrm{n}=11, \mathrm{r}=0,64, \% 95$ güvenilirlikle, $\mathrm{P}<0,05)$ ve $\mathrm{Li}(\mathrm{n}=10, \mathrm{r}=0,77$, \% 99 güvenilirlikle, $\mathrm{P}<0,01$ ) elementleri için belirtgen bitki olarak biyojeokimyasal prospeksiyonda kullanılabileceği saptanmıştır. Ayrıca $\mathrm{Cr}, \mathrm{B}, \mathrm{Sr}, \mathrm{Pb}, \mathrm{Cu}$ ve Li için belirtgen bitki olarak saptanan $P$. orientalis ve $P$. australis bitki türleri ile toprak arasındaki inter- element ilişkileri de incelenmiştir.

Anahtar Kelimeler: Biyojeokimyasal anomali, Belirtgen bitki, B-Cr-Pb-Cu-Sr-Li, Mezitli-Mersin.

E. Demir

E-posta:erkdemir@gmail.com 
Bozdoğan, Öz, Özdemir, Demir, Hatipoğlu Bağcı

\section{ABSTRACT}

Biogeochemical methods have been widely used for prospects in the recent years. This study aims to determine biogeochemical anomalities in Platanus orientalis and Phragmites australis plant species growing the Mezitli Stream. Li, B, Al, Ti, V, Cr, Mn, Fe, Co, Ni, Cu, Zn, As, Se, Rb, Sr, Mo, Cd, Sn, Cs, Ba and $\mathrm{Pb}$ element content of leaves and twigs of P. orientalis and P.australis, soil and stream water samples taken from 8 stations in Mezitli (Mersin) area were determined with inductively coupled plasma-mass spectrometry (ICP-MS). The result of the statistical analyses show that P. orientalis plant species(on twigs) can also be used as an indicator plant for $B(n=10, r=0,76, \% 99$ reliability, $P<0,01), C r(n=$ 12, $r=-0,67, \% 95$ reliability, $P<0,05), S r(n=9, r=0,72, \% 9599$ reliability, $P<0,05)$ and $P b(n=$ $11, r=0,63, \% 95$ reliability, $P<0,05)$ for biogeochemical prospecting. At the same time; $P$. australis plant species (on twigs) can be also used as an indicator plant for $\mathrm{Cu}(n=11, r=-0,66, \% 95$ reliability, $P<0,05), C r(n=11, r=0,64, \% 95$ reliability, $P<0,05)$ and $L i(n=10, r=0,77, \% 99$ reliability, $P<$ $0,01)$ for biogeochemical prospecting. Also the inter-element relationship between the P.orientalis and $P$. australis plant species which were determined as indicator plants and soil were investigated for $\mathrm{Cr}, \mathrm{B}, \mathrm{Sr}$, $\mathrm{Pb}, \mathrm{Cu}$, Li elements.

Key Words: Biogeochemical anomaly, Indicator plant, B-Cr-Pb-Cu-Sr-Li, Mezitli-Mersin.

\section{GİRIŞ}

Tarihsel olarak 1926'larda jeokimya telaffuz edilmesine rağmen ilk biyojeokimyasal çalışma, 1950'lerde Huchinson'un yaptığ1 doktora çalışmasıdır. 1965 yılından sonra ise bu alanda birçok çalışma yapılmıştır. Biyojeokimyasal yöntemle cevher aranmasında (biyojeokimyasal prospeksiyon); bitkiler, hayvanlar ve mikroorganizmalar kullanılmasina rağmen, yaygın uygulama alanları nedeni ile bitkilerden daha çok yararlanılmaktadır. $\mathrm{Bu}$ nedenle de çoğunlukla biyojeokimyasal prospeksiyon bitkilerle yapilan prospeksiyon şeklinde anlaşılmaktadır.

Cevherleşme bölgesinde sistematik olarak toplanan bitkilerin çeşitli organlarının (yaprak, dal, kök, çiçek vb.) kimyasal analizlerinin yapılması ile cevher aranmasına biyojeokimyasal prospeksiyon ve bu yöntem ile saptanan anomaliye "Biyojeokimyasal Anomali" denir (Erdman ve Kokkola, 1984; Köksoy, 1991 ve Dunn, 2007).
Jeokimyasal prospeksiyonda bir cevher yatağının yerinin saptanmasına yarayan elemente belirtgen (indikatör) element ve aranan elementi temsil eden bitkiye belirtgen (indikatör) bitki denilmektedir. Belirtgen (indikatör) bitkinin saptanmasında; cevherleşme bölgesinde toprak, su, kayaç, dere çökeli vb. gibi örneklerdeki element miktarı ile bitkideki element miktarı arasındaki doğrusal ilişkiden yararlanılmakta, örnek sayısına göre korelasyon katsayısının \% 95 ve \% 99 güvenilirliğine bağlı olarak Schroll (1975)'e göre belirtgen (indikatör) bitkiler saptanabilmektedir.

Literatürde, en fazla Au olmak üzere $\mathrm{Fe}, \mathrm{Zn}$, $\mathrm{Mn}, \mathrm{Cu}, \mathrm{B}, \mathrm{U}, \mathrm{Se}, \mathrm{Co}$ ve Ni gibi elementlerin zenginleştiği belirtgen bitkiler saptanarak, bu elementlerin oluşturduğu maden yatakları saptanmıştır (Brooks vd., 1979; Özdemir vd., 2003; Zorlu vd., 2004; Demirezen ve Aksoy, 2005; Gedik, 2005; Özdemir, 2005; Page vd., 2006; Özdemir vd., 2014). 
Son yıllarda maden aramalarında yaygın olarak kullanılmaya başlanan biyojeokimyasal yöntemler kullanılarak gerçekleştirilen bu çalışma, Mezitli Deresi (Mersin) boyunca Doğu çınarı (Platanus orientalis) ve Kamış (Phragmites australis) bitkilerinde biyojeokimyasal anomalilerin incelenmesi amacı ile yapılmış ve bu bitkilerin belirtken bitki olup olmadıkları araştırılmıştır.

\section{ÇALIŞMA ALANININ JEOLOJISİ}

Mezitli-Mersin Kiyı akifer sistemi ile bu akifer sisteminin drenaj alanında yer alan jeolojik birimler, Toros Dağ Oluşum Kuşağı'nın
Ecemiş Fayı güney kesiminde yer alır ve bu kuşağın jeolojik özelliklerini taşır. Palaeozoyik yaşlı metamorfikler (mermer, şist, kuvarsit), Üst Kretase döneminde bölgeye yerleşen ofiyolitik melanj, Oligosen-Miyosen-Pliyosen döneminde karasal, geçiş ve denizel ortam çökelleri (kireçtaş1-kumtaş1-kiltaş1-konglomeramarn-jips), Kuvaterner yaşlı karasal ve geçiş ortamı çökelleri ile morfolojik birimler bölgenin doğu ve güney kesimlerinde yaygın olarak görülmektedir. Birimlerin yaşlıdan gence yüzey yayılımları genel olarak kuzeyden güneye doğrudur. Çalışma bölgesinin yer bulduru haritası Şekil 1'de, bölgenin jeoloji haritası ise Şekil 2'de verilmiştir (Şenol ve Duman, 1998).

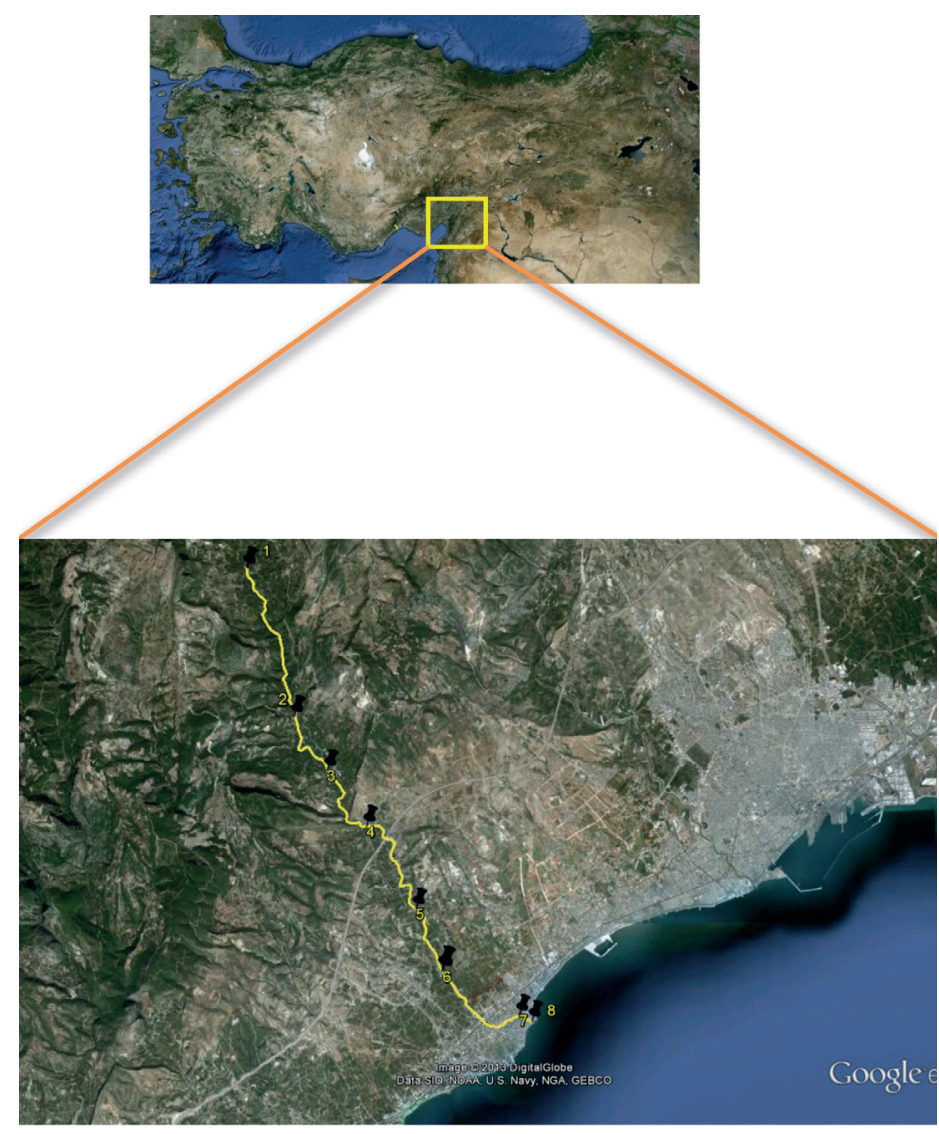

Şekil 1. Çalışma bölgesinin yer bulduru haritası.

Figure 1. Location map of the study area. 
Bozdoğan, Öz, Özdemir, Demir, Hatipoğlu Bağcı

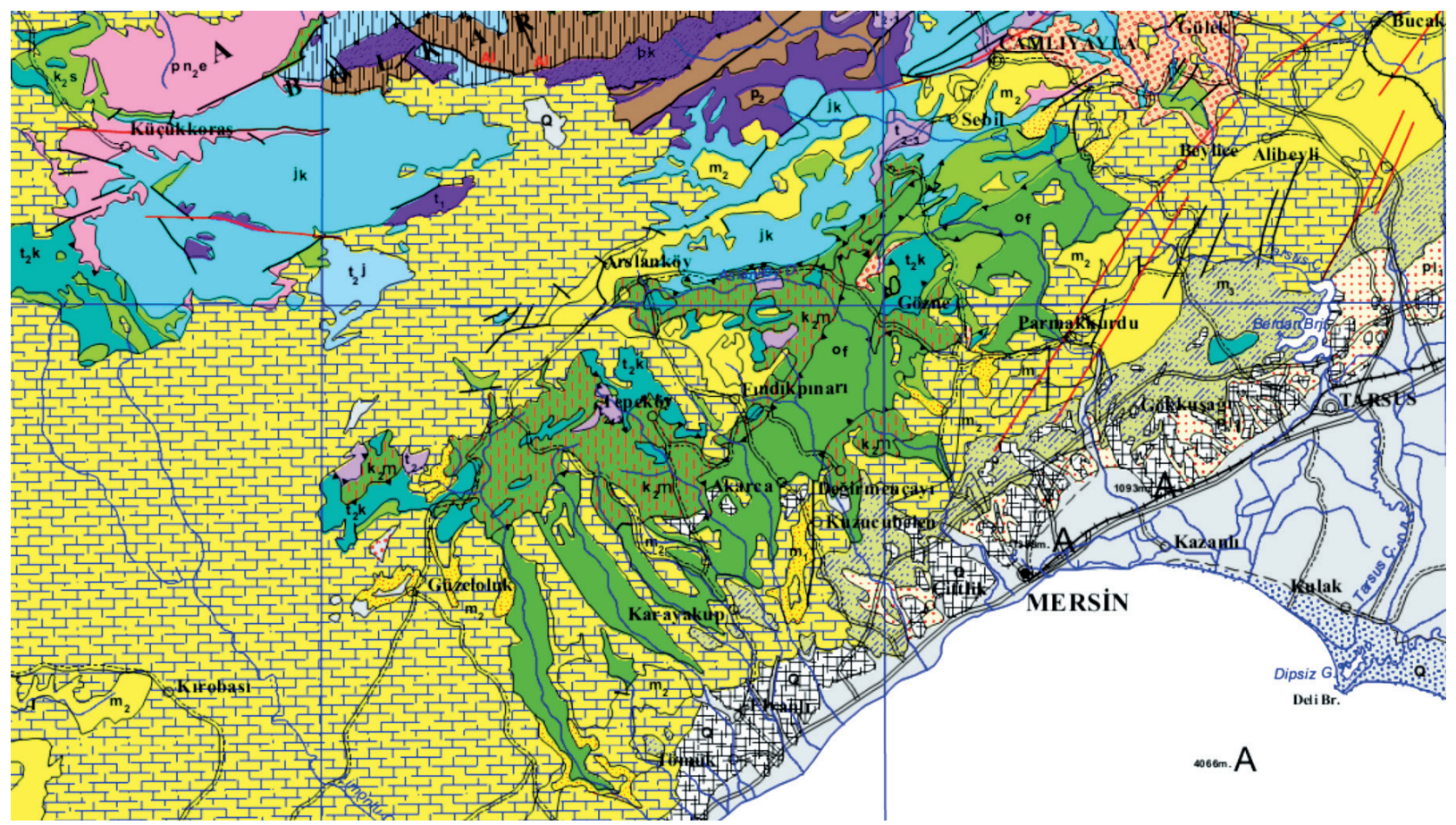

Şekil 2. İnceleme alanının jeoloji haritası (Şenol ve Duman 1998'den değiştirilerek).

Figure 2. Geology map of the study area (modified from Şenol and Duman, 1998).

İnceleme alanında Șenol ve Duman (1998) tarafından yapılan ayrıntılı jeolojik çalışmalar özetlenmiştir.

Bölgeyi temsil eden formasyonlar ve genel özellikleri tabandan yüzeye doğru aşağıdaki gibidir:

Karahamzauşağı Formasyonu: Bölgenin temelini oluşturan Paleozoik yaşlı, sığ-derin denizde çökelmiş ve daha sonra metamorfizmaya uğramış metamorfik kireçtaşları, mermer, kuvarsit, şist ve dolomitlerden oluşmaktadır. Yaklaşık kalınlığı 500 metredir. Düzenli bir tabakalanma gösteren formasyon güneydoğuya eğimlidir.

\section{Mersin Ofiyolitik Melanjı: Mersin'in} kuzeyinde genellikle derin vadilerde görülür.
Gabro, harzburjit, dunit, diyabaz, radyolarit ve derin deniz sedimanlarının yanı sira ofiyolitlerin yerleşimi sırasında havzaya taşınan Permiyen, Jura, Kretase yaşlı kayaç bloklarını içermektedir. Bölgedeki ofiyolitlerde genellikle serpantinleşme hâkim olmuştur. Üst Kretase yaşlı olan Ofiyolojik Melanj, altındaki ve üstündeki birimlerle diskordandır. Kalınlığ 200 metre civarındadır.

Gildirli Formasyonu: Birbirleri ile yanal ve düşey geçişli, alt kesimlerde konglomera-kumtaşı birimi, orta kesimlerde silttaş1-kiltaşı birimi ve üst kesimlerde killi kireçtaş1-marn birimi şeklinde belirgin üç kaya biriminden oluşmuştur. Alt-Orta Miyosen yaşlı olan formasyon akarsu, göl, sığ deniz ve lagün ortamlarında çökelmiştir. Paleotopografyanın özelliklerine bağlı olarak kalınlık 1 ile 175 metre arasında değişmektedir. 
Karaisalı Formasyonu: Beyaz, açı gri renkli, killi, erime boşluklu, yer yer iyi katmanlı resifal kireçtaşlarından oluşmuştur. Alt-Orta Miyosen boyunca bölgede hüküm süren kıyı ortamında (karbonatlı kıyı/resif) çökelmiştir. Formasyon Miyosen öncesi birimler üzerine uyumsuz, Gildirli Formasyonu üzerine ise geçişli ve transgresif olarak gelmektedir. Formasyon üzerine Güvenç Formasyonu geçişli olarak gelmektedir. Kalınlığı, aşınma koşullarına bağlı olarak değişim göstermekte ve yayılımlarında düzensizlik görülmektedir.

Güvenç Formasyonu: Yeşilimsi-gri, gri, beyazıms1-sarı renklerde olan, alt bölümde killi kireçtaş1-marn, üst bölümlerde kiltaş1silttaşı birimlerinin egemen olduğu çökellerden oluşmuştur. Resif önü sı ̆g deniz-derin deniz ortamlarında çökeldiği söylenebilir. Alt dokanağında yanal ve dikey geçişli Karaisalı Formasyonu, üst dokanağında ise uyumlu ve girik olarak Kuzgun Formasyonu bulunmaktadır. Miyosenin Langiyen-Sarravaliyen-Tortoniyen katlarını temsil eden formasyonun kalınlığ1 50 ile 600 metre arasında değişmektedir.

Kuzgun Formasyonu: Sarımsı beyaz, yeşilimsi, siyahımsı gri renklerdeki formasyon, kumtaşıkonglomera-resifal kireçtaşı, tüfit, kiltaş1marn-silttaş1 olmak üzere belirgin üç birimden oluşmuştur. Miyosen'in Tortoniyen, Messiniyen katlarını temsil eden formasyon kıyı-sı̆̆ deniz, derin deniz ortamlarında çökelmiş olup kalınlığ1 50-1500 metre arasındadır. Alttaki formasyonlar üzerine uyumlu ve geçişli olarak gelir. Üst dokanağında ise Handere Formasyonu uyumlu ve geçişli olarak bulunmaktadır.

Handere Formasyonu: Beyazıms1, sarıms1, yeşilimsi gri ve siyahımsı gri renkli olan; kiltaşımarn-silttaşı, fosilli oolitik kireçtaşı, alçıtaşı
(Jips) ve kumtaşı-konglomera olmak üzere belirgin dört birimden oluşmuştur. Kuzgun formasyonu üzerine uyumlu olarak gelmektedir. Kalınlığ1 50-500 metre arasında olup, kuraksıcak iklimler ile s1k sık değişen küçük ölçekli transgresyon ve regresyonlar sonucu oluşan siğ deniz, geçiş (kıyı, lagün, delta, gelgit) ve akarsu ortamlarında çökelmiştir.

Kuvaterner Birimleri: Karasal ve geçiş ortamı koşullarının hüküm sürdügü Kuvaterner döneminde oluşan birimler farklı fasiyes özellikleri göstermektedir. KalabriyenSiciliyen zamanında oluşan birimler (alüvyon yelpazesi çökelleri/yüksek seki konglomeraları, kıyı çökelleri ve kaliş) ve Tirreniyen-güncel oluşan birimler (yamaç molozları, akarsu seki konglomeraları, delta çökelleri, kıyı çökelleri, kumul ve pedolojik oluşumlar) olarak ayrılmıştır (Şenol ve Duman, 1998).

Mezitli'de bulunan akarsuların su rejimleri dağlar ve platoların bazı bölümlerinin orman örtüsünden yoksun olması nedeniyle genellikle düzensizdir. Yüksek oranda mil taşımalarına karşın akarsular iyi nitelikli sulama suyu özellikleri göstermektedir.

Mezitli Deresi (Liparis Çayı) kuzeydeki tepelerden yağışlarla beslenmekte ve Mezitli İlçesinden geçerek denize dökülmektedir. Fransız gezginlerinden Langlois'un 'Kilikya'da Gezi” adlı kitabında Liparis Çayı'nın suyunun şifalı olduğu; kenarının defne, yabani asma ve yabani güllerle süslü bulunduğunu yazmaktadır.

\section{MATERYAL VE YÖNTEM}

Temmuz (2012) ve Şubat (2013) ayları içerisinde Mezitli (Mersin) bölgesindeki Mezitli Deresi'nden bitki, toprak ve su örnekleri 
sistematik olarak alınmış ve örnek yerleri GPS ile saptanıp 1/25000 ölçekli jeoloji haritaları üzerine işaretlenmiştir. Alınan bitki ve toprak örnekleri numaralandırılarak laboratuvara getirilmiştir. Bitki, toprak ve su örnekleri farklı örnek hazırlama yöntemleri ile analize hazırlanmıştır. Örneklerin kimyasal analizleri için AGILENT 7500ce marka ICP-MS cihazı kullanılmıştır.

Çalışma bölgesinden alınan su örneklerinde pH ve EC (elektriksel iletkenlik) ölçümleri ile, sulama suyu açısından standartlarının değerlendirilmesi amaçlanmıştır.

Araziden alınarak laboratuvara getirilen bitki örnekleri saf su ile yıkanarak kağıt zarflar içerisinde $80 \mathrm{C}^{\circ}$ 'de 24 saat etüvde kurutulmuş ve neminden arındırılmıştır. Kurutma işleminden sonra bitkiler dal, yaprak gibi organlarına ayrılarak ögütülmüştür. Aynı örnekler element analizleri için hazırlanmış olup örneklerde organik madde yakılması olarak bilinen kül etme tekniği uygulanmıştır. Bu yöntem, örneğin uygun kaplarda belirli bir sıcaklıkta ve belirli bir sürede tutularak organik maddelerin uzaklaştırılması sonucu elde edilen kalıntının inorganik bir asit içerisinde çözülerek analiz edilmesi ilkesine dayanmaktadır. Organik maddelerin tamamen uzaklaştırılmasında; öyle bir kül etme sıcaklığı seçilmelidir ki; kül etme süresince analizi yapılan elementin mümkün olduğunca az kayba uğraması ve elde edilen kalıntının asitte çözünmesi istenmektedir (Özdemir, 1992; Hoenig ve Borger, 1983).

Benton ve Jones (1984) tarafindan geliştirilen yöntem esas alınarak; etüvde kurutulmuş olan bitki örnekleri, organlarına (yaprak ve dal) ayrılarak yaklaşık 3000 g (kuru ağırlık üzerinden) tartıldıktan sonra porselen krozeye konulmuş ve kül firında $50 \mathrm{C}$ /saat hızla
$550 \mathrm{C}$ /saat 'e kadar getirilmiş ve bu sıcaklıkta 10 saat bekletilmiştir. Daha sonra krozeler soğutulmuş ve krozeler içerisindeki kül üzerine 5 ml HC1 çözeltisi eklendikten sonra çözülerek meydana gelen karışım balon jojeye aktarılarak deiyonize su (saf su) ile $25 \mathrm{ml}$ 'ye tamamlanmıştır. Çözeltideki element miktarları ICP-MS ile saptanmıştır. Elde edilen sonuçlar bitki organının (dal-yaprak) kuru ağırlığında ppm (mg/L, mg/kg) ve ppb olarak hesaplanmıştır. Çalışma alanından alınan bitki örneklerinin üzerinde yetiştiği topraklardan yaklaşık 200 gr kadar alınarak laboratuvara getirilmiştir. Kağıt zarflar içerisinde $80 \mathrm{C}^{\circ}$ ye ayarlanan etüvde yaklaşı 10 saat kurutulmuştur. Kurutulan toprak örnekleri -80 mesh'lik elekte elenerek element içeriklerinin saptanması için ön hazırlık tamamlanmıştır. Toprak örneklerinin kimyasal analizleri Brooks vd. (1992)'den yararlanılarak yapılmıştır. Bu amaçla; kurutulmuş toprak örneklerinden yaklaşık $0,1 \mathrm{~g}$ tartıldıktan sonra polietilen kaba konulmuş ve üzerine $10 \mathrm{ml}$ derişik $\mathrm{HF}+\mathrm{HNO}_{3}$ (1:1) karışımı eklendikten sonra 1sıtıcı tabla üzerinde kuruyuncaya kadar buharlaştırılmış ve üzerine $7 \mathrm{ml} \mathrm{HCl} \mathrm{(1:1)} \mathrm{eklenmiş} \mathrm{ve} \mathrm{buharlaştırma}$ işlemi tekrarlanmıştır. Elde edilen kalıntı $7 \mathrm{ml}$ HC1 de çözündükten sonra saf su ile 25 ml'ye tamamlanarak elde edilen çözeltilerde element içerikleri ICP-MS cihazı ile ölçülmüştür.

$\mathrm{Su}$ örnekleri için araziden alınan örnekler, 500 ml'lik örnek kaplarına konularak her örnek için alınan noktaya göre numaralandırılmış ve ICP-MS cihazı ile element içerikleri belirlenmiştir. Ayrıca su örneklerinde arazide $\mathrm{pH}$ ve sicaklık değerleri Mettler Toledo (FG2-Basic - FiveGo ${ }^{\mathrm{TM}} \mathrm{pH}$ Meter) cihaz ile yerinde ve EC değerleri de yine aynı gün Mettler Toledo marka cihaz ile laboratuvarda okutulmuştur (Çizelge 1).

Toprak, bitki ve su örneklerindeki element 
Çizelge 1. Dere suyu için pH, sıcaklık ve elektriksel iletkenlik (EC) değerleri.

Table 1. Ph, temperature and electrical conductivity (EC) values for river water.

\begin{tabular}{|l|c|c|c|l|l|c|c|}
\hline $\begin{array}{c}\text { Temmuz } \\
\mathbf{2 0 1 3}\end{array}$ & $\mathbf{p H}$ & $\begin{array}{c}\text { Sicaklık } \\
\mathbf{C}^{\circ}\end{array}$ & $\begin{array}{c}\mathbf{E C} \\
\boldsymbol{\mu} \text { S/cm }\end{array}$ & \multicolumn{1}{c|}{$\begin{array}{c}\text { Şubat } \\
\mathbf{2 0 1 3}\end{array}$} & $\mathbf{p H}$ & $\begin{array}{c}\text { Sicaklık } \\
\mathbf{C}^{\circ}\end{array}$ & $\begin{array}{c}\mathbf{E C} \\
\boldsymbol{\mu} \mathbf{S} / \mathbf{c m}\end{array}$ \\
\hline A1-1 DERE & 7.76 & 21.3 & 619 & $\mathbf{A 2 - 1}$ DERE & 8.66 & 8.4 & 560 \\
\hline A1-2 DERE & 6.81 & 16.5 & 649 & A2-2 DERE & 8.68 & 9.5 & 545 \\
\hline A1-3 DERE & 7.59 & 27.6 & 611 & A2-3 DERE & 8.60 & 10.5 & 555 \\
\hline A1-4 DERE & 7.48 & 26.3 & 690 & A2-4 DERE & 8.61 & 10.4 & 578 \\
\hline A1-5 DERE & 7.53 & 34.5 & 928 & A2-5 DERE & 8.55 & 11.8 & 610 \\
\hline A1-6 DERE & 7.41 & 29.5 & 766 & A2-6 DERE & 8.10 & 25.0 & 834 \\
\hline A1-7 DERE & 8.01 & 28.4 & 675 & A2-7 DERE & 8.62 & 12.1 & 585 \\
\hline A1-8 DERE & 7.45 & 33.1 & 547 & A2-8 DERE & 8.68 & 13.4 & 664 \\
\hline
\end{tabular}

(Li, B, Al, Ti, V, Cr, Mn, Fe, Co, Ni, Cu, Zn, As, Se, Rb, Sr, Mo, Cd, Sn, Cs, Ba ve $\mathrm{Pb}$ ) düzeyleri ICP-MS ile belirlendikten sonra elde edilen veriler istatiksel olarak değerlendirilerek literatürdeki normal değerlerle karşılaştırılmıştır. Ayrica Schroll (1975)'e göre \% 95 ve \% 99 verimlilikle sonuçlar tartışılmıştır.

Bilgisayarda Microsoft Office Excel programı yardımıyla toprakta artan element derişimine karş1lık bitkide saptanan element derişimi grafiksel olarak ifade edilmiş, elde edilen grafiğe ait korelasyon katsayıları (r) hesaplanmıştır.

Deneysel olarak saptanan korelasyon katsayısı değeri $\left(\mathrm{r}_{\text {deneysel }}\right)$, Schroll (1975) tarafından \% 95 güvenilirlikle verilen teorik korelasyon katsayısı $\left(\mathrm{r}_{\text {teorik }}\right)$ değerleri ile karşılaştırılmıştır (Schroll, 1975). Bitki ve toprak arasında iyi bir korelasyon olabilmesi için $r_{\text {deneysel }}>r_{\text {teorik }}$ olmas1 gerekmektedir.

\section{BULGULAR ve TARTIŞMA}

Bitki organlarındaki element derişimi prospeksiyon amaciyla kullanılacaksa, bitkilerdeki element derişimi ile üzerinde yetiştiği toprağın element derişimi arasında doğrusal bir ilişki olmalıdır. Bu ilişkiyi sağlayan bitkilere belirtgen bitki (indikatör bitki) denilmektedir (Köksoy, 1991; Brooks vd., 1995; Dunn, 2007). Belirtgen bitkilerin saptanması amaciyla Mezitli (Mersin) bölgesinden alınan $P$. australis ve $P$. orientalis bitkilerinin yaprak, dal ve toprak örneklerindeki element konsantrasyonları ppm (mg/L) olarak Çizelge 3, 4, 5, 6 ve 7'de verilmiştir. Şekil 10'da ise bu bitki türlerinin fotoğrafları sunulmuştur. Ayrıca Şekil 3, 4, 5, 6, 7, 8 ve 9'da toprak ve bitkilerin her bir element için ayrı ayrı kimyasal analizleri sonucu elde edilen veriler istatistiksel olarak değerlendirilerek aşağıda sunulmuştur. 


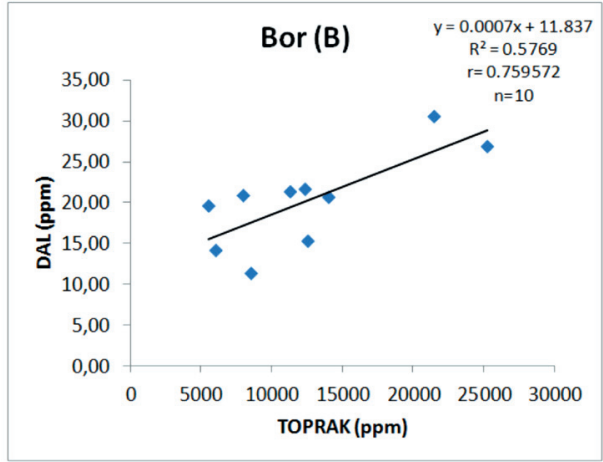

Şekil 3. P. orientalis bitkisinin dalındaki B ile topraktaki $\mathrm{B}$ arasındaki ilişki.

Figure 3. The relationship between $B$ in the soil and $B$ in the twigs of $P$. orientalis plant.

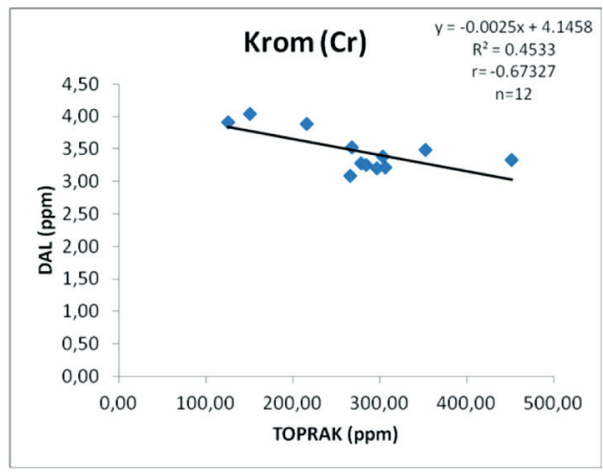

Şekil 4. P. orientalis bitkisinin dalındaki Cr ile topraktaki $\mathrm{Cr}$ arasındaki ilişki.

Figure 4. The relationship between $\mathrm{Cr}$ in the soil and $\mathrm{Cr}$ in the twigs of P. orientalis plant.

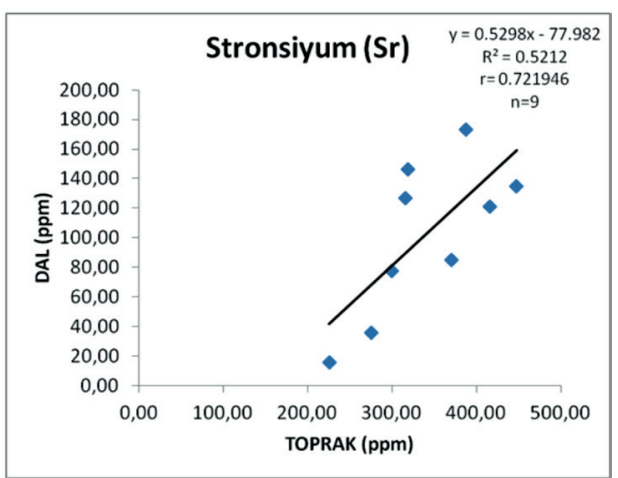

Şekil 5. P. orientalis bitkisinin dalındaki Sr ile topraktaki Sr arasındaki ilişki.

Figure 5. The relationship between $\mathrm{Sr}$ in the soil and $\mathrm{Sr}$ in the twigs of $P$. orientalis plant.

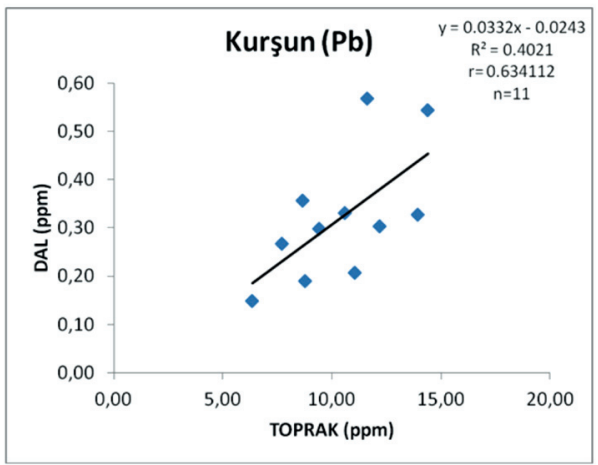

Şekil 6. P. orientalis bitkisinin dalındaki $\mathrm{Pb}$ ile topraktaki $\mathrm{Pb}$ arasındaki ilişki.

Figure 6. The relationship between $\mathrm{Pb}$ in the soil and $\mathrm{Pb}$ in the twigs of $P$. orientalis plant.

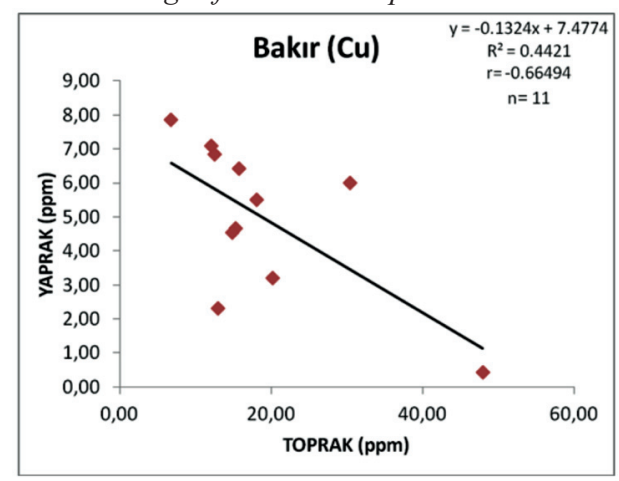

Şekil 7. P. australis bitkisinin yaprağındaki $\mathrm{Cu}$ ile topraktaki $\mathrm{Cu}$ arasındaki ilișki.

Figure 7. The relationship between $\mathrm{Cu}$ in the soil and $\mathrm{Cu}$ in the leafs of P. australis plant.

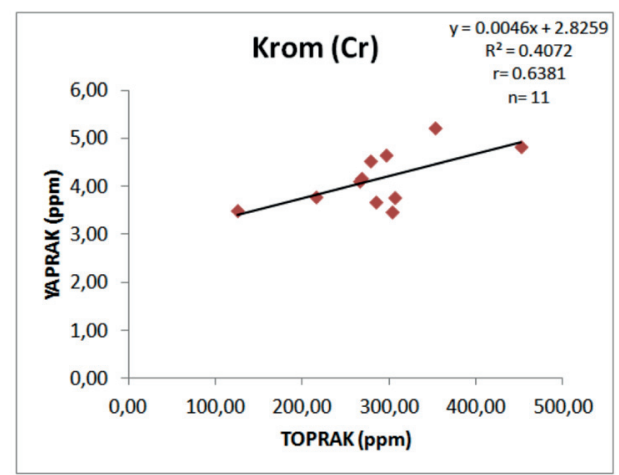

Şekil 8. P. australis bitkisinin yaprağındaki $\mathrm{Cr}$ ile topraktaki $\mathrm{Cr}$ arasındaki ilişki.

Figure 8. The relationship between $\mathrm{Cr}$ in the soil and $\mathrm{Cr}$ in the leafs of P. australis plant. 


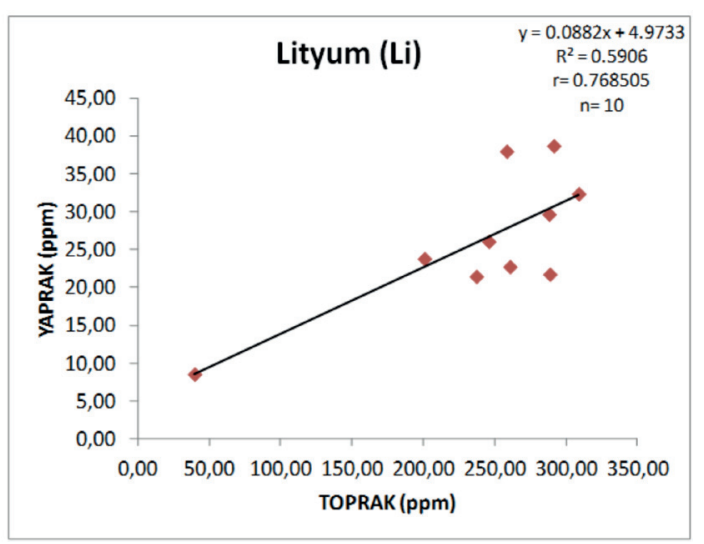

Şekil 9. P. australis bitkisinin yaprağındaki Li ile topraktaki Li arasındaki ilişki.

Figure 9. The relationship between Li in the soil and Li in the leafs of $P$. australis plant.

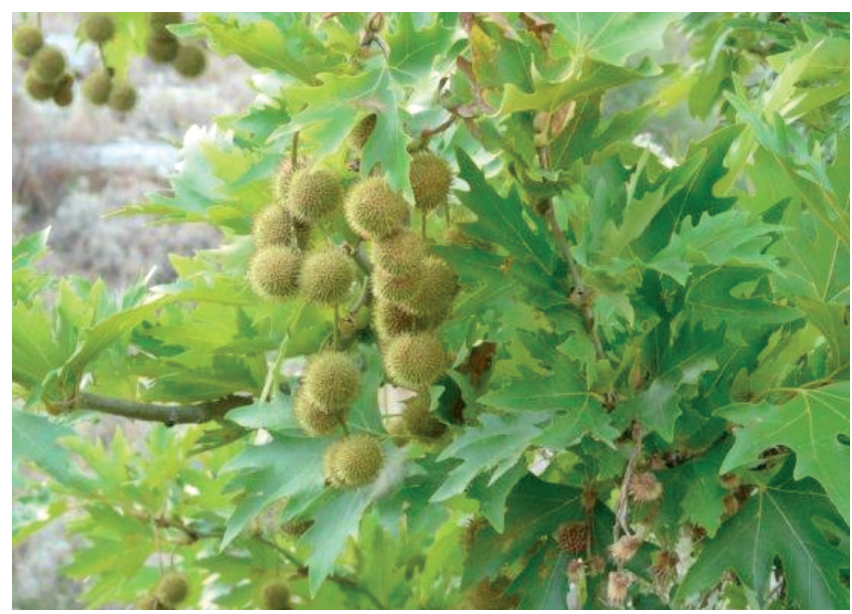

Doğu çınarı (Platanus orientalis)

Şekil 10. P. australis ve $P$. orientalis bitki türlerinin fotoğrafları. Figure 10. Photos of P. australis and P. orientalis plant species.

Bor (B), bitkiler için gerekli besin elementlerinden biridir ve bitkiler tarafindan $\left(\mathrm{BO}_{3}\right)^{-3}, \quad\left(\mathrm{~B}_{4} \mathrm{O}_{7}\right)^{-2}$ şeklinde topraktan alınır (Yürekli ve Aslanargun, 2002). Topraklarda B'un alınabilirliliğini etkileyen bazı etmenler vardır. Bunlardan en önemlileri toprak pH'1, tekstürü ve antagonizmdir. pH'ın artışıyla B'un bitkilerce alınımında azalma görülür. Bitkiler tarafından
B'un alınımını mümkün kılan optimum $\mathrm{pH}$ sinır1 5,0 -7,5'tir (Y1lmaz, 2004). Kacar (1984) tarafından toprakların yararlı B içeriğinin 0,1-6 ppm arasında olduğunu, bitkilerin B içeriklerinin 3-60 ppm arasında değişiklik gösterdiğini, normal bitkilerin çok olağan dışı hallerde 100 ppm'den fazla B içerdiklerini, bu değerin 200 ppm'e çıktığı durumlarda B'un toksik etkisinin ortaya çıkabileceğini belirtilmiştir.

$P$. orientalis bitkisinin üzerinde yetiştiği topraklardan alınan örneklerde B konsantrasyonu için 984 ile 25225 pm arasında değişen değerler saptanmıştır. Bitkinin dalında ise B konsantrasyonu 11,38 ile 30,59 ppm arasinda

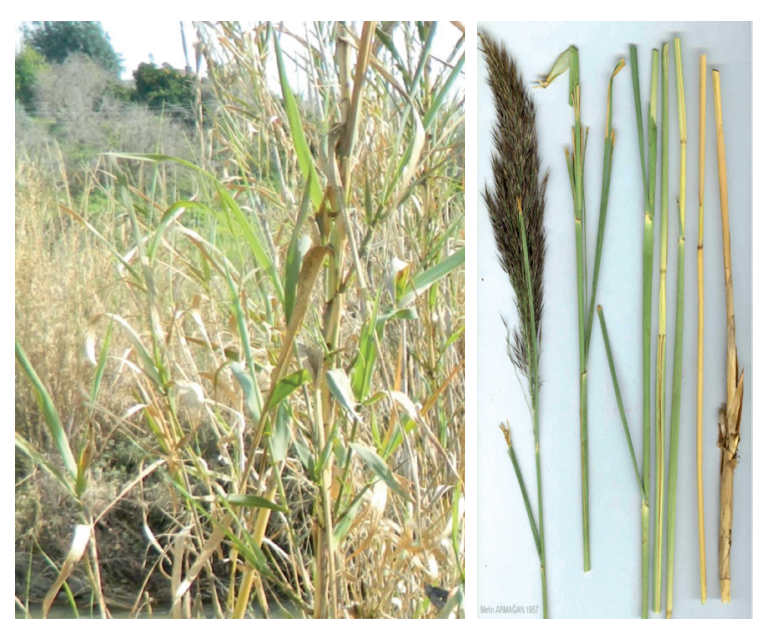

Kamış (Phragmites australis)

değişmektedir. Bu çalışmada Bor için P. orientalis bitkisinin dalındaki $\mathrm{B}$ ile topraktaki $\mathrm{B}$ düzeyi arasında $(\mathrm{n}=10, \mathrm{r}=0,76, \% 99$ güvenilirlikle $\mathrm{P}<0,01)$ pozitif korelasyon olduğu saptanmıştır (Şekil 3). Buna göre $P$. orientalis bitki türünün dalının B için belirtgen bitki olabileceği söylenebilir. Toprakta B değerinin literatüre göre çok yüksek olmasına rağmen bitkide 
normal değerlerde olması ve çizilen grafiğin doğrusallık göstermesi, bu bitkinin belirtgen bitki olabileceğini ancak bitkinin, toprakta aşırı miktarda bulunan B'u bünyesine alamamasının nedenlerinin araştırılması gerekir.

Krom (Cr), bitkiler için gerekli olmayan ancak insan ve hayvanlar için mutlak gerekli olan bir elementtir. Kitasal Yerkabuğu ortalama 80 ppm Cr içermektedir. Serpantin ve ultrabazik magmatitler 3400 ppm'e kadar Cr içermektedir. Ana materyale göre değişmekle birlikte toprakta 5-100 ppm oranlarında bulunur. Bitkide ise kuru maddede 100 ppm bulunması birçok yüksek bitki için toksik etki yaratmaktadır (Özbek vd., 1995). Rose vd. (1979)'a göre bitkide Cr kuru ağırlık üzerinden yaklaşık 150 ppb'dir (Bu değer kül ağırlık üzerinden 6 ppm'e eşittir. Yaklaşık olarak; kuru ağırlık değeri x $40=$ kül değeri).

$P$. orientalis ve $P$. australis bitkilerinin üzerinde yetiştiği topraklardan alınan örneklerde Cr konsantrasyonu için 125 ile 452 pm arasında değişen değerler saptanmıştır. $P$. orientalis bitkisinin dalında 3 ile $4 \mathrm{ppm}$ arasinda, $P$. australis bitkisinin yaprağında ise 3 ile 5 ppm arasında $\mathrm{Cr}$ konsantrasyonu değişmektedir. Krom için $P$. orientalis bitkisinin dalındaki Cr ile topraktaki Cr düzeyi arasında $(\mathrm{n}=12, \mathrm{r}=-0,67$, $\% 95$ güvenilirlikle, $\mathrm{P}<0,05)$ negatif korelasyon olduğu (Şekil 4) ve $P$. australis bitkisinin yaprağındaki $\mathrm{Cr}$ ile topraktaki $\mathrm{Cr}$ düzeyi arasında ise $(n=11, r=0,64, \% 95$ güvenilirlikle, $\mathrm{P}<0,05)$ pozitif korelasyon olduğu saptanmıştır (Şekil 8 ). Buna göre $P$. orientalis (dal) ve $P$. australis (yaprak) bitki türlerinin $\mathrm{Cr}$ için belirtgen olabileceği söylenebilir.

Doğada serbest olarak bulunmayan Stronsiyum'un (Sr), bitki gelişimi için gerekli olup olmadığına dair bir bilgi bulunmamaktadır.
Ancak Rose vd. (1979) tarafından Sr içeriğinin magmatik kayaçlarda 5,8-465 ppm, sedimenter kayaçlarda 20-610 ppm arasında olduğunu, bu değerin topraklarda $67 \mathrm{ppm}$, bitkilerde ise 4-45 ppm arasında değiştiği belirtilmiştir.

$P$ orientalis bitkisinin üzerinde yetiştiği topraklardan alınan örneklerde $\mathrm{Sr}$ konsantrasyonu için 225 ile 671 ppm arasında değişen değerler saptanmıştır. Bitkinin dalında ise Sr konsantrasyonu 16 ile 173 ppm arasında değişmektedir. Bu değerlerin normal değerlerin üzerinde olmasının yanında $P$. orientalis bitkisinin dalındaki $\mathrm{Sr}$ düzeyi ile topraktaki $\mathrm{Sr}$ düzeyi arasinda ( $\mathrm{n}=9, \mathrm{r}=0,72, \% 95$ güvenilirlikle, $\mathrm{P}$ $<0,05)$ pozitif korelasyon olduğu saptanmıştır (Şekil 5). Buna göre $P$. orientalis bitki türünün dalının Sr için belirtgen bitki olabileceği söylenebilir.

Kurşun $(\mathrm{Pb})$ elementi bitkiler için mutlak gerekli olmayıp, toprakta $15-40 \mathrm{ppm}$ dozunda bulunur. Topraktaki kurşun konsantrasyonu 150 ppm'i aşmadığı sürece insan ve bitki sağlığ 1 açısından tehlike oluşturmamaktadır (Dürüst vd. 2004). Kurşun elementi, hücre turgoru ve hücre duvarı stabilitesini olumsuz etkilemesi, stoma hareketlerini ve yaprak alanını azaltması nedeniyle bitki su rejimini etkilemektedir. Aynı zamanda kökler tarafından tutulmasından ve kök gelişimini azaltmasından dolayı bitkilerin katyon ve anyon alımını azaltmakta ve bu nedenle de besin alımını etkilemektedir (Sharma ve Dubey, 2005). Rose vd. (1979)'a göre Pb'nin toprakta 17 ppm, bitkide ise 750 ppb olduğu belirtilmektedir.

$P$ orientalis bitkisinin üzerinde yetiştiği topraklardan alınan örneklerde $\mathrm{Pb}$ konsantrasyonu için 6 ile 14 ppm arasında değişen değerler saptanmıştır. Bitkinin dalında ise $\mathrm{Pb}$ konsantrasyonu 0,2 ile 1,2 ppm arasinda 
değişmektedir. $\mathrm{Bu}$ çalışmada kurşun için $P$. orientalis bitkisinin dalındaki $\mathrm{Pb}$ düzeyi ile topraktaki $\mathrm{Pb}$ düzeyi arasında $(\mathrm{n}=11, \mathrm{r}=0,63$, $\% 95$ güvenilirlikle, $\mathrm{P}<0,05)$ pozitif korelasyon olduğu saptanmıştır (Şekil 6). Buna göre $P$. orientalis bitki türünün dalının $\mathrm{Pb}$ için belirtgen bitki olabileceği söylenebilir.

Özbek vd. (1995) tarafindan, bakur $(\mathrm{Cu})$ içeriğinin, kayaçlarda genel olarak 4-90 ppm arasında değişen değerlerde olduğu, bu değerlerin $\mathrm{Cu}$ 'ca temiz topraklarda 2-40 ppm, Cu'ca kirlenmiş topraklarda ise 1000 ppm olabileceği, bitkilerde ise $\mathrm{Cu}$ içeriği genellikle 2-20 ppm arasında değiştiği belirtilmiştir. Ayrıca, bakırın toprakta fazla bulunduğu durumlarda, bitkilere toksik etki yapmasının yanı sıra, bitkiler tarafından demirin alınımını da güçleştirdiği belirtilmektedir (Bozcuk, 1986).

$P$ australis bitkisinin üzerinde yetiştiği topraklardan alınan örneklerde $\mathrm{Cu}$ konsantrasyonu için 7 ile 48 ppm arasında değişen değerler saptanmıştır. Bitkinin yaprağında ise $\mathrm{Cu}$ konsantrasyonu 0,4 ile $23 \mathrm{ppm}$ arasinda değişmektedir. Bakır için P. australis bitkisinin yaprağındaki $\mathrm{Cu}$ düzeyi ile topraktaki $\mathrm{Cu}$ düzeyi arasinda ( $\mathrm{n}=11, \mathrm{r}=-0,66, \% 95$ güvenilirlikle, $\mathrm{P}<0,05)$ negatif korelasyon olduğu saptanmıştır (Şekil 7). Buna göre Phragmites australis bitki türünün yaprağının $\mathrm{Cu}$ için belirtgen bitki olabileceği söylenebilir. Yapılan bu çalışmayla, toprak ve bitki değerlerinin toksik düzeyde kabul edilemeyeceği, ancak bitki ve toprak arasında, istatistiksel anlamda bir ilişki olduğu için, toksik değerlerde de bitkinin bu istatistiksel ilişkiye uygun davranabileceği düşünülebilir.

Rose vd. (1979) tarafından, bitki beslenmesinde destekleyici eser elementler içerisinde bulunan lityumun (Li) magmatik kayaçlarda 40 ppm, sedimanter kayaçlarda 5-66 ppm, topraklarda 22 ppm, bitkilerde ise kuru ağırlık üzerinden 155 ppb olduğu belirtilmiştir (bitkilerde kül ağırlık üzerinden 6,2 ppm). Nagaraju ve Karimulla'nın (2002), Andra Pradesh'de (Hindistan) yapmış oldukları çalışmada, topraktaki 2-4 ppm Li içeriğine karşılık bitkilerde 75 ppb Li içeriği saptanmıştır ( kül ağırlık üzerinden 3 ppm).

$P$ australis bitkisinin üzerinde yetiştiği topraklardan alınan örneklerde $\mathrm{Li}$ konsantrasyonu için 40 ile 309 ppm arasında değişen değerler saptanmıştır. Bitkinin yaprağında ise Li konsantrasyonu 8,5 ile 53 ppm arasında değişmektedir. Bu çalışmada lityum için $P$. australis bitkisinin yaprağındaki Li düzeyi ile topraktaki Li düzeyi arasında ( $\mathrm{n}=10$, $\mathrm{r}=0,77, \% 99$ güvenilirlikle, $\mathrm{P}<0,01)$ pozitif korelasyon olduğu saptanmıştır (Şekil 9). Buna göre $P$. australis bitki türünün yaprağının Li için belirtgen bitki olabileceği söylenebilir.

Çalışma kapsamında alınan su örnekleri için arazide ölçülen $\mathrm{pH}$, Sicaklık ve laboratuvarda ölçülen EC değerleri çizelge 1'de sunulurken, çizelge 2, 3, 4 ve 5'de bitki ve toprak örneklerinin kimyasal analiz sonuçları, çizelge 6'da su örnekleri için element düzeyleri ve çizelge 7'de su örnekleri için anyon düzeyleri verilmiştir. 
Bozdoğan, Öz, Özdemir, Demir, Hatipoğlu Bağcı

ล פ ท

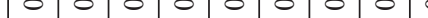
क 言 离 氙

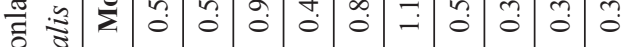

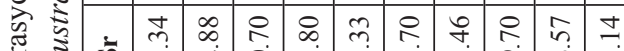

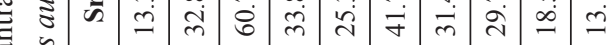

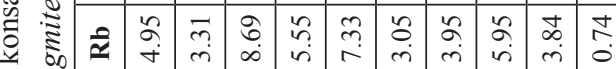

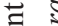

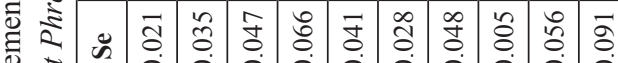

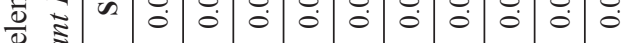

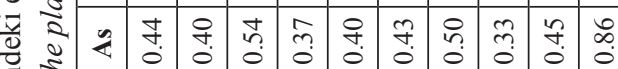
E

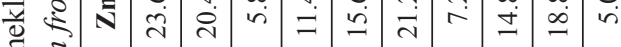

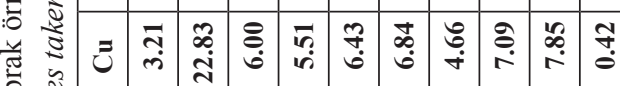

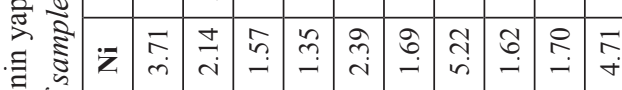

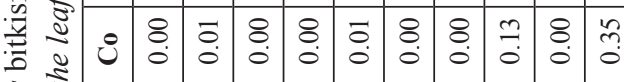
ป दे क्ष

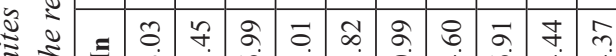

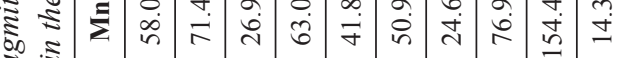
‡

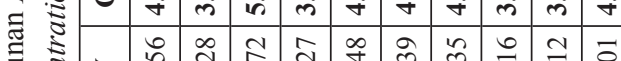

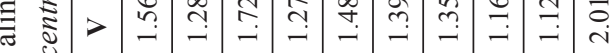

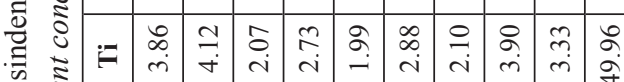
:

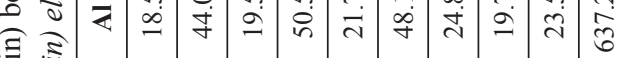

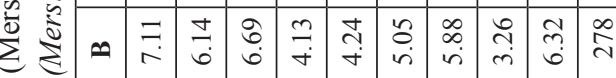

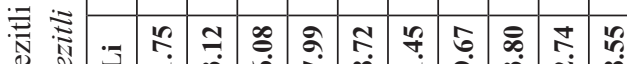

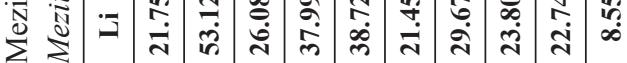

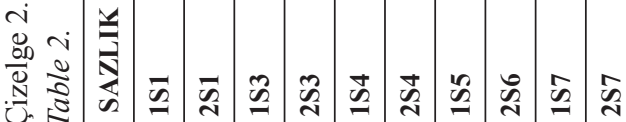

\begin{tabular}{|c|c|c|c|c|c|c|c|c|c|c|c|c|c|c|}
\hline$\stackrel{2}{2}$ & సु & 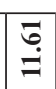 & 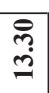 & $\stackrel{\mathscr{p}}{r}$ & \begin{tabular}{|l} 
\\
$\dot{J}$
\end{tabular} & 旁 & Fे & $\begin{array}{l}\text { ț } \\
\text { d. }\end{array}$ & 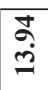 & $\stackrel{\text { Iิ }}{\text { İ }}$ & $\stackrel{\hat{\sigma}}{\infty}$ & in & 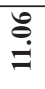 & \\
\hline ๓็ & 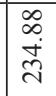 & \begin{tabular}{|l}
0 \\
0 \\
0 \\
0
\end{tabular} & $\begin{array}{l}\stackrel{n}{c} \\
\stackrel{p}{m}\end{array}$ & \begin{tabular}{|l|}
8 \\
8 \\
8
\end{tabular} & 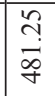 & $\begin{array}{l}\text { â } \\
\stackrel{\sim}{y} \\
y\end{array}$ & $\begin{array}{l}\hat{\tilde{f}} \\
\dot{0} \\
\dot{0}\end{array}$ & \begin{tabular}{|l}
0 \\
$\dot{\theta}$ \\
$\dot{y}$
\end{tabular} & 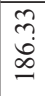 & 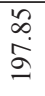 & $\begin{array}{l}\text { ஜे } \\
\text { ले }\end{array}$ & 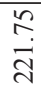 & $\begin{array}{l}\text { in } \\
\text { तु } \\
\text { in }\end{array}$ & \begin{tabular}{|l|}
$\infty$ \\
$\infty$ \\
0 \\
0
\end{tabular} \\
\hline$\tilde{u}$ & $\stackrel{\mathbb{I}}{\leftrightarrows}$ & $\begin{array}{l}\text { i } \\
\text { in }\end{array}$ & 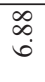 & $\stackrel{ \pm}{\stackrel{I}{S}}$ & 人ิ & পুo & $\underset{+}{\dot{+}}$ & ले. & $\underset{f}{f}$ & $\stackrel{i}{i}$ & $\begin{array}{l}\stackrel{8}{\circ} \\
+\end{array}$ & $\stackrel{\circ}{\circ}$ & $\frac{1}{6}$ & กิ \\
\hline है & $\stackrel{i n}{i}$ & $\stackrel{m}{n}$ & $\stackrel{\overbrace{}}{\sim}$ & बे & $\begin{array}{l}\stackrel{\leftrightarrow}{\tilde{r}} \\
+\end{array}$ & ते & $\begin{array}{l}0 \\
0 \\
\dot{0}\end{array}$ & $\stackrel{\overrightarrow{\hat{i}}}{\mathrm{i}}$ & $\underset{m}{\Delta}$ & $\stackrel{t}{i}$ & \ั & $\stackrel{8}{\circ}$ & 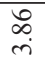 & ن \\
\hline$\tilde{J}$ & $\begin{array}{l}0 \\
\tilde{b} \\
0 \\
0\end{array}$ & $\begin{array}{ll} \\
0 \\
0\end{array}$ & $\stackrel{?}{0}$ & $\hat{\widehat{a}}$ & 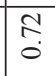 & $\stackrel{0}{0}$ & $\frac{\mathfrak{0}}{\stackrel{t}{0}}$ & $\hat{0}$ & $\stackrel{?}{?}$ & 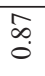 & $\begin{array}{l}8 \\
0 \\
0\end{array}$ & gे & $\stackrel{n}{a}$ & m \\
\hline$\stackrel{\ominus}{\Sigma}$ & $\begin{array}{l}\bar{\infty} \\
\stackrel{I}{U}\end{array}$ & 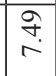 & $\stackrel{\hat{a}}{a}$ & $\stackrel{\infty}{\stackrel{\infty}{-}}$ & $\vec{\sigma}$. & $\bar{a}$ & $\stackrel{\tilde{C}}{=}$ & $\underset{\infty}{\vec{\infty}}$ & \begin{tabular}{|l}
$\stackrel{8}{0}$ \\
$\stackrel{0}{\circ}$
\end{tabular} & $\stackrel{n}{=}$ & $\underset{\infty}{\vec{\infty}}$ & $\underset{\therefore}{\Rightarrow}$ & $\stackrel{q}{q}$ & $\&$ \\
\hline is & 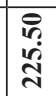 & 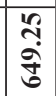 & 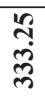 & 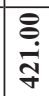 & 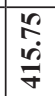 & 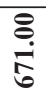 & 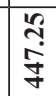 & 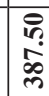 & 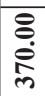 & $\begin{array}{l}\text { dि } \\
\frac{\infty}{m}\end{array}$ & $\begin{array}{l}\text { ते } \\
\text { ลें }\end{array}$ & $\underset{\mathrm{g}}{\stackrel{\mathrm{g}}{\mathrm{m}}}$ & 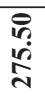 & 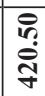 \\
\hline జิ & $\stackrel{\vec{J}}{\stackrel{J}{\Xi}}$ & $\mid \begin{array}{l}\stackrel{n}{n} \\
m\end{array}$ & 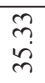 & 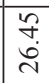 & $\begin{array}{l}n \\
\stackrel{n}{8} \\
\text {. }\end{array}$ & $\begin{array}{l}\infty \\
\stackrel{\infty}{n} \\
\stackrel{n}{n}\end{array}$ & $\begin{array}{l}\tilde{O} \\
\dot{\delta} \\
\tilde{e}\end{array}$ & \begin{tabular}{|l|}
$\infty$ \\
$\ddot{i}$ \\
|
\end{tabular} & $\mid \begin{array}{l}\text { â } \\
\text { wn } \\
m\end{array}$ & 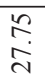 & 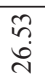 & $\begin{array}{l}\stackrel{8}{2} \\
\text { ले }\end{array}$ & $\begin{array}{l}\tilde{\lambda} \\
\stackrel{\sim}{N}\end{array}$ & $\pi$ \\
\hline$\ddot{n}$ & $\stackrel{\text { }}{\rightarrow}$ & $\stackrel{\vec{n}}{\longrightarrow}$ & $\vec{\sigma}$ & $\stackrel{n}{n}$ & in & $\stackrel{8}{9}$ & $\stackrel{\text { I }}{\text { I }}$ & $\vec{i}$ & 㞼 & $\stackrel{?}{?}$ & $\stackrel{?}{\rightarrow}$ & $\stackrel{8}{\circ}$ & $\underset{i}{\stackrel{\bullet}{i}}$ & $\stackrel{8}{\circ}$ \\
\hline$\psi^{n}$ & $\begin{array}{l} \pm \\
\dot{I} \\
\end{array}$ & $\begin{array}{l} \\
0 \\
0 \\
\end{array}$ & $\begin{array}{l}8 \\
\text { in } \\
\text {. }\end{array}$ & $\frac{2}{6}$ & 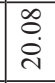 & $\begin{array}{l}\overrightarrow{\bar{m}} \\
\infty \\
-\end{array}$ & $\begin{array}{l}n \\
\text { nn } \\
n\end{array}$ & 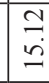 & $\begin{array}{l} \\
\stackrel{2}{ \pm} \\
\end{array}$ & $\begin{array}{l}\text { nे } \\
\dot{I}\end{array}$ & $\begin{array}{l}5 \\
\text { s. }\end{array}$ & $\begin{array}{l}\stackrel{R}{0} \\
\dot{8}\end{array}$ & $\begin{array}{l}\text { ñ } \\
\text { ה̀ }\end{array}$ & \\
\hline งี & $\begin{array}{l}\stackrel{n}{\infty} \\
\stackrel{\infty}{=}\end{array}$ & 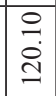 & 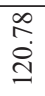 & 产 & 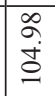 & 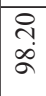 & 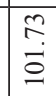 & 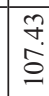 & 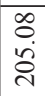 & 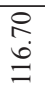 & & 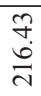 & $\begin{array}{l}\stackrel{\circ}{\circ} \\
\stackrel{0}{0}\end{array}$ & $\tilde{\theta}$ \\
\hline ש & $\begin{array}{l}\tilde{\text { సิ }} \\
\text { ஸे }\end{array}$ & ing & 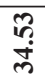 & $\begin{array}{l}\stackrel{8}{\infty} \\
\dot{\infty} \\
\dot{\infty}\end{array}$ & 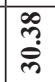 & $\begin{array}{l}\hat{a} \\
\dot{\theta} \\
\underline{\theta}\end{array}$ & $\begin{array}{l}\stackrel{2}{a} \\
\stackrel{2}{2}\end{array}$ & 岕 & 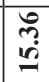 & $\begin{array}{l}\tilde{S} \\
\mathbf{I}\end{array}$ & $\begin{array}{l}\underset{+}{+} \\
\stackrel{+}{ \pm}\end{array}$ & $\stackrel{\sim}{\mathcal{I}}$ & مْ & 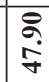 \\
\hline z & $\vec{b}$ & $\widehat{్}$ & $\begin{array}{l}\text { : } \\
\text { de }\end{array}$ & $\stackrel{\infty}{\stackrel{\infty}{\sigma}}$ & స్ & ڤ્ & 宇 & \begin{tabular}{|l} 
\\
$b$ \\
+
\end{tabular} & $\overline{\hat{F}}$ & ơ & 古 & 齐 & 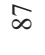 & - \\
\hline ن & 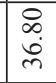 & $\begin{array}{l}8 \\
\text { m. } \\
\end{array}$ & $\begin{array}{l}m \\
\vec{i}\end{array}$ & $\begin{array}{l}\stackrel{R}{0} \\
\stackrel{0}{0}\end{array}$ & $\begin{array}{l}\text { ते } \\
\text { ते }\end{array}$ & $\begin{array}{l}\stackrel{\partial}{\partial} \\
\infty \\
-\end{array}$ & $\begin{array}{l}\circ \\
\text { à } \\
\text { an }\end{array}$ & $\begin{array}{l}\delta \\
\text { I } \\
\text { in }\end{array}$ & 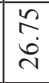 & 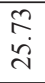 & $\begin{array}{l}\text { ते } \\
\text { Sิ }\end{array}$ & $\begin{array}{l}\stackrel{g}{+} \\
\tilde{\imath}\end{array}$ & $\stackrel{\circ}{\circ}$ & \\
\hline : & $\frac{n}{n}$ & 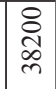 & 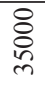 & $\mid \begin{array}{l}\hat{\sigma} \\
\underline{\infty}\end{array}$ & 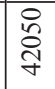 & 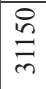 & $\begin{array}{l}\text { D } \\
\text { m }\end{array}$ & 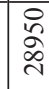 & 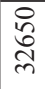 & 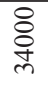 & 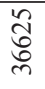 & $\begin{array}{l}\text { \&े } \\
\text { లn }\end{array}$ & $\begin{array}{l}\underbrace{\infty}_{\infty} \\
\stackrel{\infty}{I} \\
\end{array}$ & \\
\hline
\end{tabular}

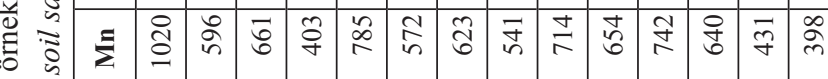

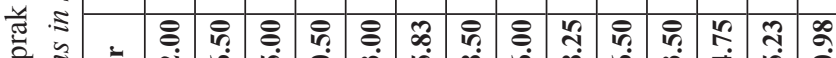

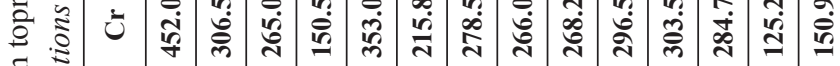

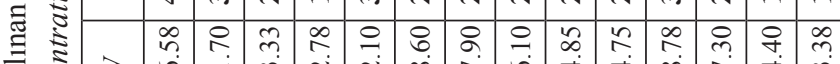

ฮี

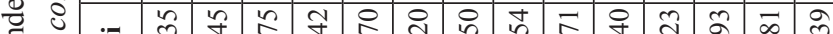

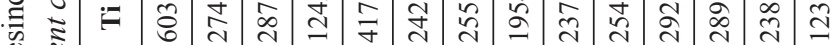

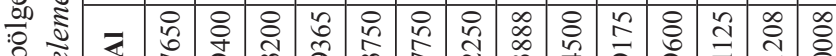

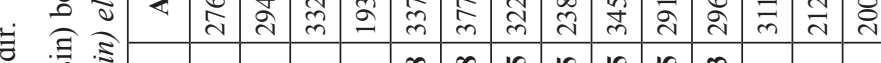

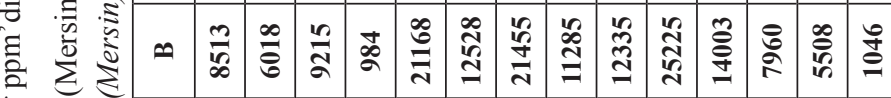
竞

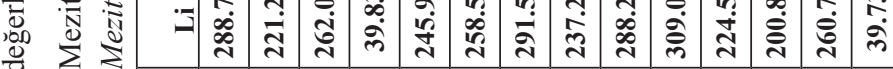

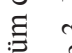

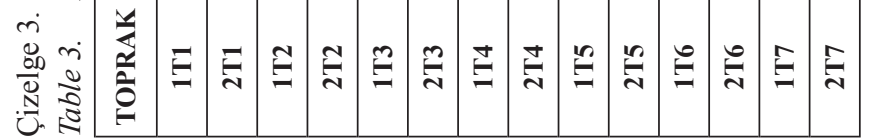




\begin{tabular}{|c|c|c|c|c|c|c|c|c|c|c|c|c|c|}
\hline$\hat{z}$ & $\frac{10}{6}$ & in & $\tilde{\Omega}$ & 党 & ঙ્গి & ల్ & ্ֻণ & $\stackrel{\widehat{m}}{\stackrel{0}{0}}$ & 户্: & $\frac{9}{9}$ & $\stackrel{m}{\dddot{m}}$ & $\overline{\text { Tี }}$ & $\hat{\overbrace{}}$ \\
\hline ๑็ & $\begin{array}{l}\text { I } \\
\text { in }\end{array}$ & $\stackrel{2}{\stackrel{2}{\sim}}$ & $\underset{\infty}{ \pm}$ & 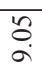 & 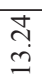 & $\stackrel{n}{a}$ & $\begin{array}{l}n \\
a \\
a\end{array}$ & mे & $\begin{array}{l}\stackrel{0}{9} \\
0\end{array}$ & ઼ָ & $\begin{array}{l}\vec{a} \\
\stackrel{j}{j}\end{array}$ & \begin{tabular}{l}
$\infty$ \\
\multirow{2}{b}{}
\end{tabular} & $\stackrel{n}{n}$ \\
\hline$\tilde{u}$ & $\overrightarrow{0}$ & $\stackrel{\infty}{\circ}$ & $\stackrel{8}{\circ}$ & $\vec{\circ}$ & do & $\hat{0}$ & $\overline{0}$ & $\stackrel{8}{0}$ & $\stackrel{8}{8}$ & $\stackrel{8}{\circ}$ & $\stackrel{8}{\circ}$ & $\stackrel{0}{\circ}$ & $\frac{9}{0}$ \\
\hline कี & $\stackrel{\circ}{\circ}$ & $\stackrel{\circ}{\stackrel{0}{\circ}}$ & oे & $\begin{array}{l}\stackrel{\circ}{\circ} \\
\stackrel{0}{*}\end{array}$ & $\overrightarrow{0}$ & $\begin{array}{l}\infty \\
0 \\
0\end{array}$ & $\stackrel{8}{\circ}$ & oे. & $\begin{array}{l}\stackrel{1}{0} \\
0\end{array}$ & $\stackrel{5}{\circ}$ & $\begin{array}{l}\infty \\
\stackrel{0}{\circ}\end{array}$ & o. & $\begin{array}{l}0 \\
0 \\
0\end{array}$ \\
\hline U & $\ddot{0}$ & $\ddot{0}$ & SO & $\widetilde{\delta}$ & & $\stackrel{\tilde{o}}{\circ}$ & 0 & $\begin{array}{l}0 \\
0 \\
0\end{array}$ & 范 & $\stackrel{8}{\circ}$ & $\overrightarrow{0}$ & $\bar{\sigma}$ & $\vec{a}$ \\
\hline
\end{tabular}

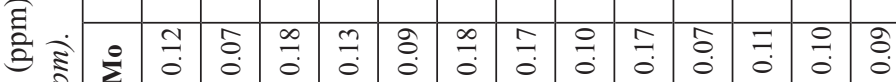
馬 至吾的

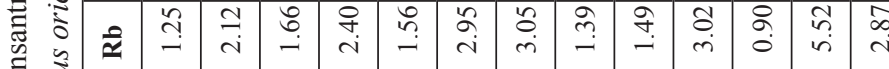

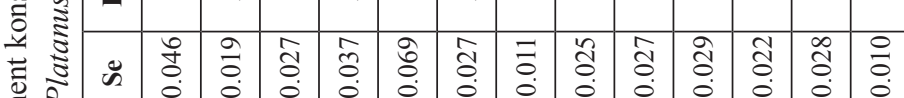

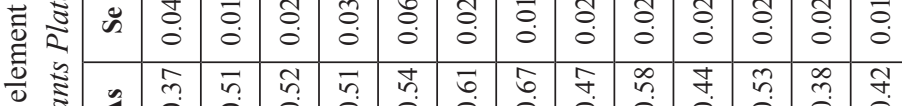
$\frac{2}{2}$

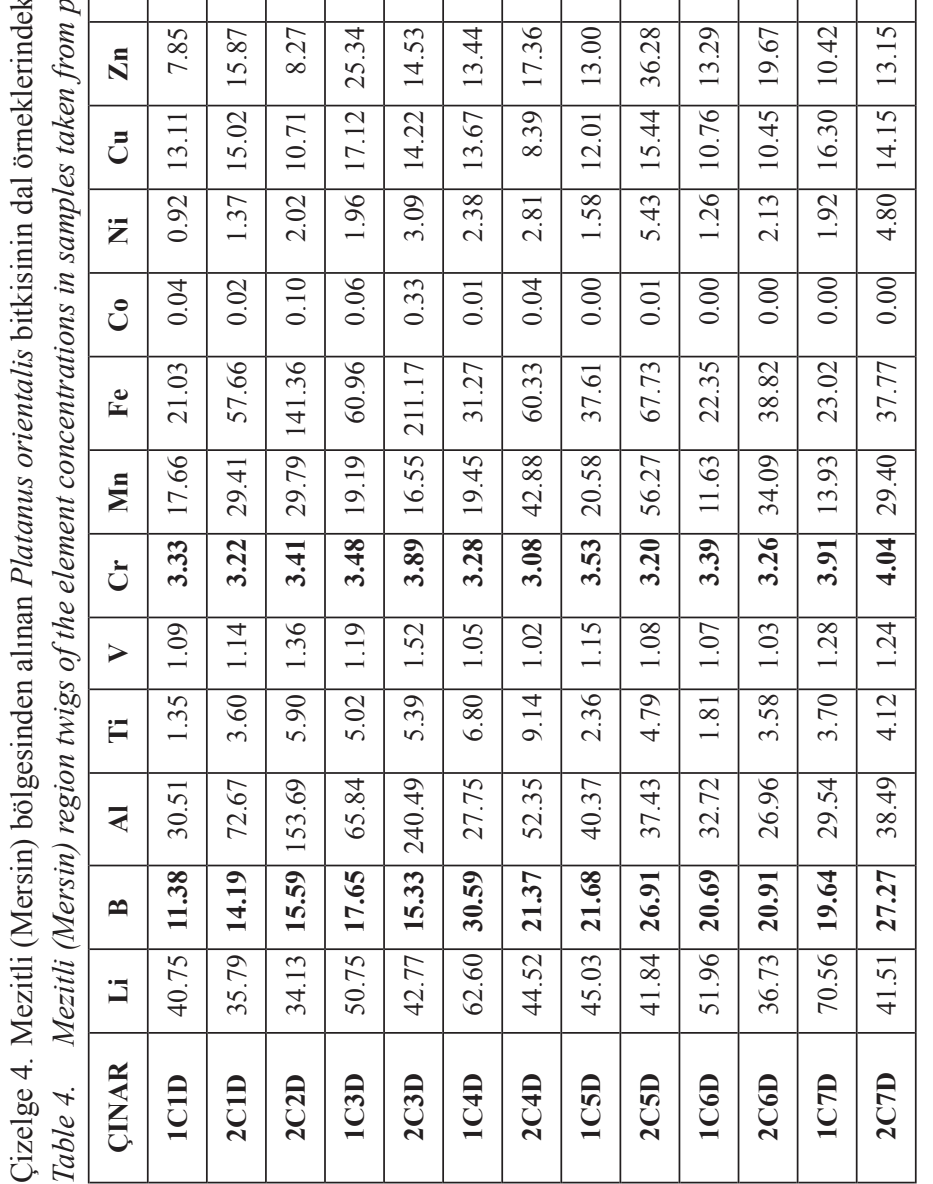

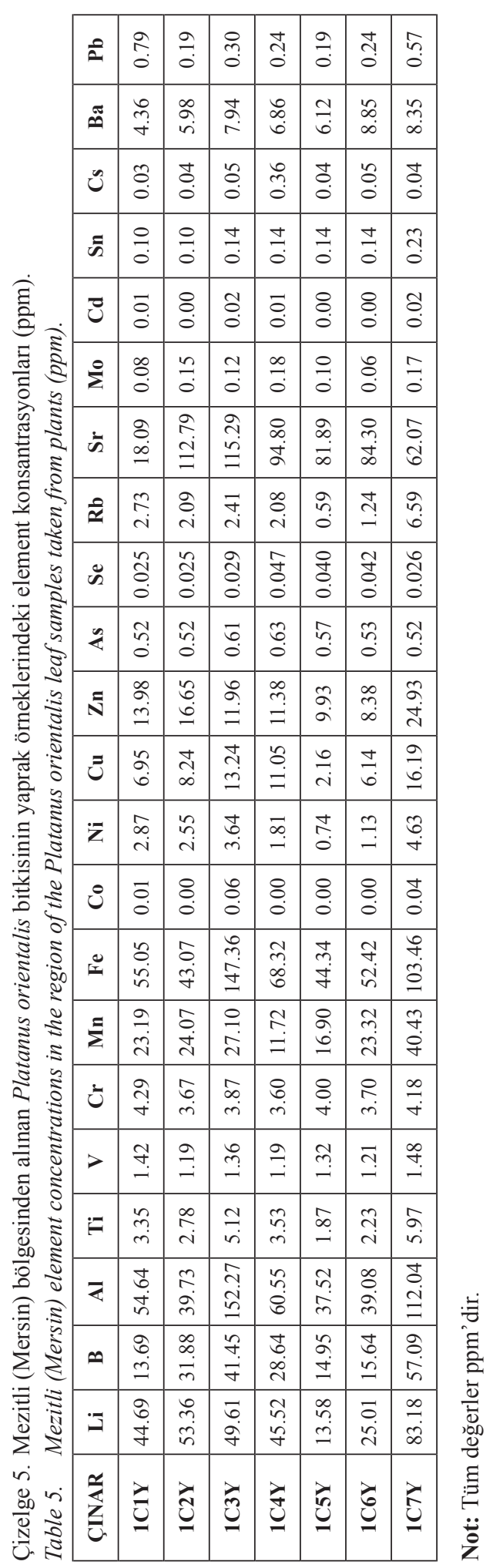


Bozdoğan, Öz, Özdemir, Demir, Hatipoğlu Bağcı

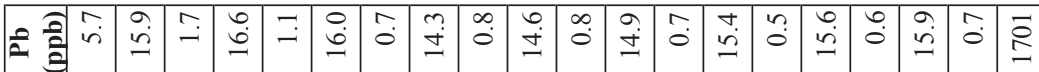
Æ̊

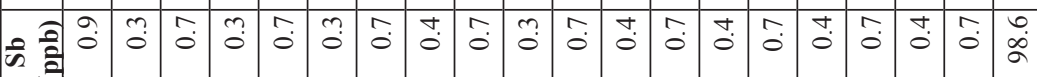

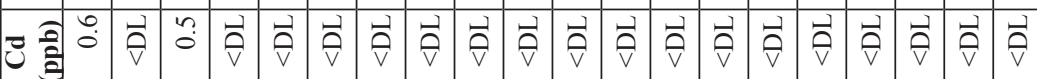

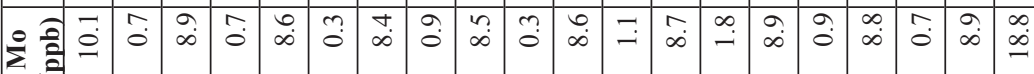

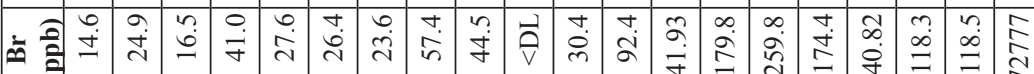

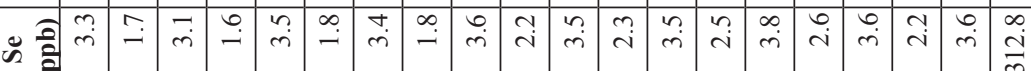

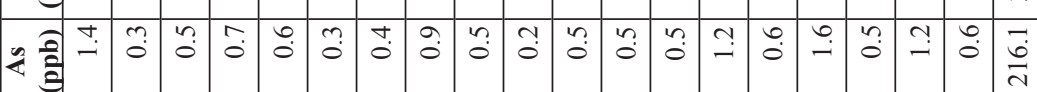

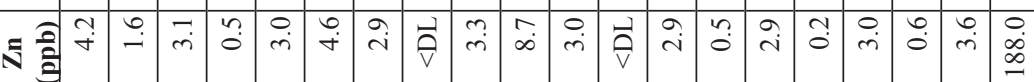

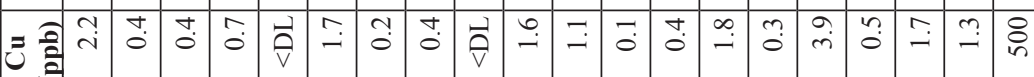

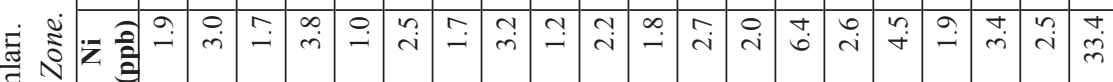
家

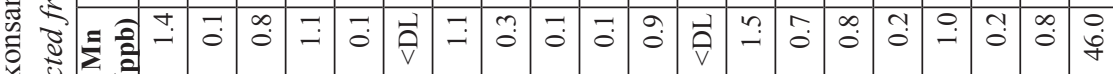
苾 $\frac{10}{2}$ 吾

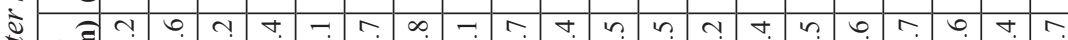
要

F

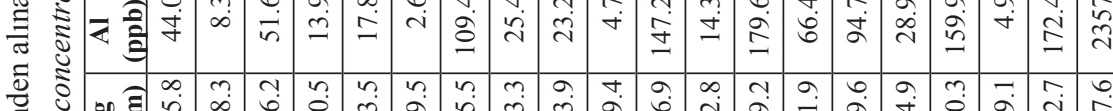
言 范 竞 衰

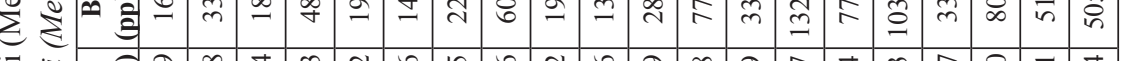
言

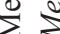
(0) $\underbrace{}_{0}$ 
Çizelge 7. Mezitli (Mersin) bölgesinden alınan su örneklerindeki anyon düzeyleri.

Table 7. Mezitli (Mersin) anion levels in water samples collected from the Zone.

\begin{tabular}{|c|c|c|c|c|c|c|c|}
\hline SU & $\begin{array}{l}\text { Fosfat } \\
(\mathrm{ppm})\end{array}$ & $\begin{array}{c}\text { Amonyum } \\
\text { (ppm) }\end{array}$ & $\begin{array}{l}\text { Florür } \\
(\mathrm{ppm})\end{array}$ & $\begin{array}{l}\text { Klorür } \\
(\mathrm{ppm})\end{array}$ & $\begin{array}{l}\text { Nitrit } \\
\text { (ppm) }\end{array}$ & $\begin{array}{l}\text { Nitrat } \\
(\mathrm{ppm})\end{array}$ & $\begin{array}{l}\text { Sülfat } \\
(\mathrm{ppm})\end{array}$ \\
\hline A1-1 DERE & $<\mathrm{DL}$ & 0.0603 & 0.095 & 13.934 & $<\mathrm{DL}$ & 14.989 & 32.882 \\
\hline A1-2 DERE & $<\mathrm{DL}$ & 0.0756 & 0.117 & 20.376 & 0.021 & 14.239 & 36.289 \\
\hline A1-3 DERE & $<\mathrm{DL}$ & 0.0754 & 0.139 & 21.304 & 0.014 & 8.859 & 49.141 \\
\hline A1-4 DERE & $<\mathrm{DL}$ & 1.7886 & 0.133 & 35.874 & 0.003 & 17.723 & 93.620 \\
\hline A1-5 DERE & $<\mathrm{DL}$ & 0.1925 & 0.135 & 79.033 & 0.057 & 14.051 & 240.446 \\
\hline A1-6 DERE & $<\mathrm{DL}$ & $<\mathrm{DL}$ & 0.142 & 72.126 & 0.018 & 30.935 & 83.919 \\
\hline A1-7 DERE & $<\mathrm{DL}$ & 0.1528 & 0.085 & 60.600 & 0.099 & 71.313 & 87.247 \\
\hline A1-8 DERE & $<\mathrm{DL}$ & $<\mathrm{DL}$ & 1.812 & 35047.289 & $<\mathrm{DL}$ & 2.496 & 3824.135 \\
\hline A2-1 DERE & $<\mathrm{DL}$ & $<\mathrm{DL}$ & 0.054 & 6.720 & $<\mathrm{DL}$ & 3.349 & 15.508 \\
\hline A2-2 DERE & $<\mathrm{DL}$ & $<\mathrm{DL}$ & 0.053 & 6.708 & $<\mathrm{DL}$ & 5.080 & 18.556 \\
\hline A2-3 DERE & $<\mathrm{DL}$ & $<\mathrm{DL}$ & 0.080 & 11.381 & $<\mathrm{DL}$ & 8.154 & 13.785 \\
\hline A2-4 DERE & $<\mathrm{DL}$ & $<\mathrm{DL}$ & 0.086 & 12.078 & $<\mathrm{DL}$ & 6.325 & 49.934 \\
\hline A2-5 DERE & $<\mathrm{DL}$ & $<\mathrm{DL}$ & 0.072 & 15.498 & $<\mathrm{DL}$ & 7.809 & 62.841 \\
\hline A2-6 DERE & $<\mathrm{DL}$ & $<\mathrm{DL}$ & 0.153 & 87.164 & $<\mathrm{DL}$ & 22.988 & 80.744 \\
\hline A2-7 DERE & $<\mathrm{DL}$ & $<\mathrm{DL}$ & 0.090 & 15.681 & $<\mathrm{DL}$ & 7.286 & 58.459 \\
\hline A2-8 DERE & $<\mathrm{DL}$ & $<\mathrm{DL}$ & 0.102 & 54.020 & $<\mathrm{DL}$ & 8.142 & 66.275 \\
\hline
\end{tabular}

\section{SONUÇLAR}

Çalışma kapsamında toplanan bitki ( $P$. orientalis ve $P$. australis), toprak ve su örneklerinde Li, B, Al, Ti, V, Cr, Mn, Fe, Co, Ni, $\mathrm{Cu}, \mathrm{Zn}, \mathrm{As}, \mathrm{Se}, \mathrm{Rb}, \mathrm{Sr}, \mathrm{Mo}, \mathrm{Cd}, \mathrm{Sn}, \mathrm{Cs}, \mathrm{Ba}$ ve $\mathrm{Pb}$ elementleri için kimyasal analizler yapılmıştır. $\mathrm{Bu}$ örneklerde $\mathrm{B}, \mathrm{Cr}, \mathrm{Pb}, \mathrm{Cu}, \mathrm{Sr}$ ve Li elementleri için bitki türleri ile yetiştikleri topraklar arasında istatistiksel olarak doğrusal ilişkiler olduğu, su örneklerinin ise TSE-266 (2005) standartlarına göre normal değerlerde olduğu saptanmıştır. $\mathrm{Bu}$ kapsamda;

1. P. orientalis bitkisinin dalındaki $\mathrm{B}, \mathrm{Sr}$ ve $\mathrm{Pb}$ ile topraktaki $\mathrm{B}, \mathrm{Sr}$ ve $\mathrm{Pb}$ düzeyleri arasında pozitif korelasyon olduğu, bu bitkinin dalındaki
$\mathrm{Cr}$ ile topraktaki $\mathrm{Cr}$ düzeyi arasında ise negatif korelasyon olduğu saptanmıştır.

2. P. australis bitkisinin yaprağındaki $\mathrm{Cr}$ ve Li ile topraktaki $\mathrm{Cr}$ ve Li düzeyi arasında pozitif korelasyon olduğu, bu bitkinin yaprağındaki $\mathrm{Cu}$ ile topraktaki $\mathrm{Cu}$ düzeyi arasında ise negatif korelasyon olduğu saptanmıştır. Bu nedenle $P$. orientalis ve $P$. australis bitki türlerinin $\mathrm{B}, \mathrm{Cr}$, $\mathrm{Pb}, \mathrm{Cu}, \mathrm{Sr}$ ve Li elementleri için belirtgen bitkiler olabileceği önerilebilir.

3. Topraktaki $\mathrm{Cr}$ artışına karşın P. orientalis bitkisinin dalındaki $\mathrm{Cr}$ içeriğinde negatif yönde doğrusal azalma saptanmıştır. Bu durum, bitkinin, ortamdaki Cr arttıkça Cr'yi bünyesine doğrusal olarak o oranda az aldığını göstermektedir. 
Ayrıca bitkinin dalının, topraktaki B, Sr ve Pb'nin artışıyla birlikte bünyesine B, Sr ve Pb'yi doğrusal olarak artan miktarda alırken, Cr'yi azalan miktarda aldığı söylenebilir.

4. Topraktaki $\mathrm{Cu}$ artışına karşın P. australis bitkisinin yaprağındaki $\mathrm{Cu}$ içeriğinde negatif yönde doğrusal azalma saptanmıştır. Bitki, ortamdaki $\mathrm{Cu}$ fazlalaştıkça bünyesine $\mathrm{Cu}$ 'yu doğrusal olarak o oranda az almaktadır. Ayrıca bitkinin yaprağının, topraktaki Cr ve Li artışıyla birlikte bünyesine $\mathrm{Cr}$ ve Li'yi doğrusal olarak artan miktarda alırken, Cu'yu ise azalan miktarda aldığı söylenebilir.

5. P. orientalis $(\mathrm{B}, \mathrm{Sr}, \mathrm{Pb}$ ve $\mathrm{Cr}$ için) ve $P$. australis ( $\mathrm{Li}, \mathrm{Cu}$ ve $\mathrm{Cr}$ için) bitki türlerinin $\mathrm{B}, \mathrm{Sr}, \mathrm{Pb}, \mathrm{Li}, \mathrm{Cu}$ ve $\mathrm{Cr}$ içeren maden yataklarının biyojeokimyasal prospeksiyonunda kullanılabileceği önerilebilir.

\section{KATKI BELIRTME}

Çalışmada kullanılan örneklerin kimyasal analizlerinin yapılmasında yardımlarını esirgemeyen Yrd. Doç. Dr. Mehmet Ali KURT’a (MEÜ MEİTAM) teşekkür ederiz.

\section{KAYNAKLAR}

Bozcuk, S., 1986. Bitki Fizyolojisi (Metabolik Olaylar). Hatipoğlu Yayınları, 176 s., Ankara.

Brooks, R. R., Morrison, R. S., Reeves, R. D., Dudley, T. R., Akman, Y., 1979. Hyperaccumulation of nickel by Alyssum Linnaeus (Cruciferae). Proceedings of The Royal Society's Physical Sciences, 203, 387-403.

Brooks, R. R., Baker, A. J. M., Malaisse, F., 1992. Copper flowers. National Geographic Ressearc and exploration, 8 (3), 338-351.
Brooks , R. R., Dunn, C. E., Hall, G. E. M., 1995. Biolocical system in mineral exploration and processing. Elles Horwood Limited, $538 \mathrm{~s}$.

Benton, J., Jones, R., 1984. Developments in the measurement of trace metal in foods, in Analyses of Food contaminants. J. Gilbert, Ed., Elsevier, London and New York, $157 \mathrm{p}$.

Demirezen, D., Aksoy, A., 2005. Common hydrophyte a bioindicators of iron and manganee pollition. Ecological Indicators, 6, 388.

Dunn, C., 2007. Biogeochemistry in mineral exploration. Consulting Geochemist, $480 \mathrm{~s}$.

Dürüst, N., Dürüst, Y., Tuğrul, D., Zengin, M., 2004. Heavy Metal Contents of Pinus Radiata Trees of İzmit (Turkey). Asian Journal of Chemistry, 16 (2), 1129.

Erdman, J. A., Kokkola, M., 1984. Workshop 2: Biogeochemistry in Mineral Explorarion, Journal of Geochemical Exploration, 25, 21-40.

Gedik, T., 2005. Madenköy (Niğde/Ulukışla) ve Dolaylarının Biyojeokimyasal Anomalilerinin İncelenmesi. Yüksek Lisans Tezi, Çukurova Üniversitesi Fen Bilimleri Enstitüsü, Adana, 113 s.

Hutchinson, G. E., 1950. Survey of existing knowledge of biogeochemictry 3: The biogeochemistry of vertebrate excreta. Bulletin of the American Museum of Natural History, 96, 71-94.

Hoening, H., Borger, M., 1983. Particular problems encountered in trace metal analysis of plant by AAS, Spectrochimica Acta, 38B (5/6), 673-880.

Kacar, B., 1984. Bitki Beslenmesi. Ankara Üniversitesi Zıraat Fakültesi Yayınları, No:289, Ankara, $317 \mathrm{~s}$.

Köksoy, M., 1991. Uygulamal1 Jeokimya. Hacettepe Yayınları,Yayın No.64, Ankara, 368 s. 
Nagaraju, A., Karimulla, S., 2002. Accumulation of elements in plants and soil in and around Nellore Mica Belt, Andhra Pradesh, India - a biogeochemical study. Environmental Geology, 41, 852-860.

Özbek, H., Kaya, Z., Gök, M., Kaptan, H., 1995. Toprak Bilimi. Çukurova Üniversitesi Ziraat Fakültesi, Genel Yayın No: 73 Ders Kitapları Yayın No:16, Adana.

Özdemir, Y., 1992. Türk çaylarında kimyasal bileşimin incelenmesinde spektrofotometrik ve kromatografik yöntemlerin yeri. İnönü Üniversitesi Fen Bilimleri Enstitüsü Doktora Tezi, $178 \mathrm{~s}$.

Özdemir, Z., Zorlu, S., Ery1lmaz, F. Y., 2003. Toprakta metal kirliliğinin saptanmasında indikatör (belirleyici) bitkilerin kullanılması. 10. Y1l Sempozyumu, Mersin, 89.

Özdemir, Z., Demir, E., 2010. Fındıkpınarı-Erdemli Mersin bölgesinde nikel akümülatörü bir bitki Alyssum murale Waldst \& Kit. Jeoloji Mühendisliği Dergisi, 34 (1), 57-70.

Özdemir, Z., 2005. Pinus brutia as a biogeochemical medium to detect iron and inc in soil analysis, chromite deposits of the area Mersin, Turkey. Chemie Der Erde-Geochemitry, 65, 79-88.

Özdemir, Z., Zorlu, S., Akyıldız, M., Yücesoy Eryılmaz, F., 2014. Determination of indicator plants for boron in the Kırka (Eskişehir-Turkey) boron deposit area. International Journal of Geosciences, 5, 77-84.

Page, V., Le Bayon, R. C., Feller, U., 2006. Partitioning of zinc, cadmium, manganese and cobalt in wheat (Triticum aestivum) and lupin (Lupinus albus) and further release into the soil. Environmental and Experimental Botany, 58, 269-278.

Rose, A. W., Hawkes, H. E., Webb, J. S., 1979. Geochemistry in mineral Exploration, 2nd ed. Academic Press, New York, 657 p.

Schroll, E., (Ed)., 1975. Anallytische Geochemie Enke Verl. Bd. I. Stuttgart, 292 s.

Sharma, P., Dubey, R. S., 2005. Lead toxicity in plants. Brazilian Journal of Plant Physiology, 17 (1), 35- 52 .

Şenol, M., Duman, T. Y., 1998. Adana-Mersin dolayının jeoloji etüdü raporu.

TSE 266. Sular - İnsani Tüketim Amaçlı Sular, 2005. Türk Standardları Enstitüsü, Ankara

Yılmaz, C., 2004. Bitkisel üretimde besin elementleri. Hasad Yayıncılık Ltd. Şti, 142 s.

Yürekli, A. K., Aslanargun, B. A., 2002. Bitkilerde Mineral Beslenme Fizyolojisi. Anadolu Üniversitesi Yayınları Eskişehir, 1432, 119 s.

Zorlu, S., Çetin, E., Özdemir, Z., 2004. Gömülü cevhere rehber bitkiler. Mavi Gezegen Dergisi, 9, 37-42. 